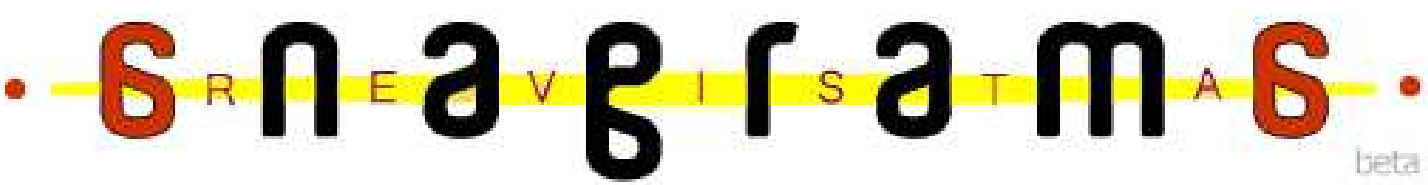

\section{O Jornalismo e o Controle da Informação: entre a censura pelo}

\section{Estado e o interior das redações}

\section{Mara Lya Simões Caetano Cabral'}

\section{Resumo}

Neste artigo, buscamos traçar reflexões acerca dos mecanismos de controle da informação que incidiram e ainda incidem sobre a produção jornalística, ao longo da História brasileira e atualmente. Pretendemos, assim, mostrar que a prática censória é um mecanismo cotidianizado no país e que seu exercício transcende os limites cronológicos da ditadura militar brasileira. E que, além da censura em sua acepção tradicional, ou seja, exercida pelo Estado, há outras formas de controle que incidem sobre a informação jornalística. Desse modo, a partir de aspectos históricos, buscaremos também situar os posicionamentos da imprensa frente ao Estado, à censura e à lógica de mercado a que estão submetidas as empresas de comunicação, refletindo sobre as perspectivas da profissão e as discussões acerca do diploma de jornalista.

Palauras-chave: Jornalismo; Liberdade de Imprensa; Censura; Controle da Informação; Diploma de Jornalista.

\section{Introdução}

Refletir sobre a história do jornalismo no Brasil, criticamente, fornece-nos importante instrumental para situar o atual cenário da produção jornalística no país e os principais desafios enfrentados pelos jornalistas hoje.

\footnotetext{
${ }^{1}$ Estudante de Graduação do $8^{\circ}$ semestre do curso de Jornalismo da Escola de Comunicações e Artes (ECA) da USP. É bolsista de iniciação científica da Fapesp junto ao projeto temático "Comunicação e Censura análise teórica e documental de processos censórios a partir do Arquivo Miroel Silveira da Biblioteca da ECA/USP", coordenado pela Prof. a Dr. ${ }^{a}$ Maria Cristina Castilho Costa, atuando no eixo de pesquisa "Liberdade de Expressão: Manifestações no Jornalismo", sob responsabilidade da professora Prof ${ }^{\mathrm{a}}$. Dr ${ }^{\mathrm{a}}$. Mayra Rodrigues Gomes. E-mail: nara.cabral@usp.br.
} 
Mais do que isso, conhecer a história da imprensa brasileira significa constatar o fato de que (assim como na imprensa mundial) o jornalismo brasileiro acompanha o desenvolvimento do capitalismo. Essa ideia é evidenciada por Nelson Werneck Sodré (1983) e também ganha contorno com o pensamento de Ciro Marcondes Filho (1986). Não pretendemos aqui ir a fundo na análise de tal questão, mas sim, levarmos em conta a constatação de suas consequências, relacionadas às condições de trabalho dos jornalistas, aos entraves impostos à sua produção e a novos impasses que são impostos ao exercício da profissão.

Assim, neste artigo, busca-se refletir sobre os principais impasses enfrentados pelos jornalistas, no passado e atualmente, os quais têm implicações sobre as rotinas de trabalho e as mensagens jornalísticas veiculadas. Para isso, busca-se partir da ideia de jornalismo enquanto espaço de mediação, tendo no horizonte experiências passadas e episódios históricos como ponto de partida para a reflexão.

Por fim, objetivamos aqui discutir as perspectivas da profissão face a uma questão posta em evidência atualmente: a não obrigatoriedade do diploma de jornalista. A partir de tal discussão, pretendemos pensar sobre as especificidades do jornalismo enquanto profissão, além dos interesses que motivam os argumentos em torno do debate sobre a necessidade ou não de formação específica ao exercício do jornalismo.

\section{Ameaças à liberdade de expressão: raízes da tradição censória}

$\mathrm{O}$ veto à palavra e o controle da produção cultural no Brasil possuem raízes que remetem aos primórdios da dominação portuguesa em terras brasileiras. Citando Sérgio Mattos, "no Brasil, a censura foi um legado da colonização" (Mattos, 2005: 99). A mesma ideia é assim explicitada por Maria Cristina Castilho Costa: "A censura tem sido uma constante na vida brasileira em razão da condição colonial que marcou quatro séculos de nossa história" (Costa, 2006: 27).

No século XVIII, por exemplo, durante a época pombalina, houve a reafirmação da política de controle ideológico e da exploração econômica características do colonialismo, com o reforço de recursos coercitivos de origem católica (Tribunal do Santo Ofício) e a criação de mecanismos de coerção de natureza laica. Em 1768, marquês de Pombal criou uma junta denominada Real Mesa Censória, cujas funções incluíam a censura de livros e a publicação do Index. Segundo Mattos, essa junta reunia as funções de três formas de 
censura já existentes anteriormente (nihil obstat eclesiástico, o Desembargo do Paço e a Inquisição) e teve seus poderes estendidos ao Brasil pela rainha dona Maria I, com autorização do papa (Mattos, 2005: 99).

No ano de 1706, o governo português adotou uma política sistemática de restrição da liberdade de imprensa na colônia. A primeira medida foi o confisco de uma tipografia no Recife. Em 1747, uma tipografia inaugurada havia um ano por Antonio Isidoro da Fonseca, no Rio de Janeiro, foi fechada pela Carta Régia de 10 de maio, a qual proibia a impressão de livros ou de papeis avulsos na colônia com o objetivo de manter fora de contestações a política absolutista portuguesa. Esse dispositivo de censura teve como consequência principal a total inexistência de órgãos de imprensa durante muitos anos do período colonial brasileiro (Mattos, 2005: 100).

Apenas com a chegada de dom João VI ao Brasil, em 1808, é que teve início a imprensa no Brasil. Naquele ano, foi criada a Imprensa Régia - a qual, no entanto, era oficial - e, junto com ela, foi implementado o primeiro ato oficial sobre a censura no Brasil (datado de 27 de setembro de 1808). Também nessa ocasião, dom João VI nomeou os primeiros censores régios, que tinham o dever de impedir qualquer publicação que atentasse contra o governo, a religião e os bons costumes (Mattos, 2005: 100).

O Correio Braziliense foi o primeiro jornal brasileiro publicado por brasileiro sem o jugo da censura portuguesa, mas, devido às críticas que fazia contra a corte do Rio de Janeiro, levou também à implantação do primeiro ato de proibição de circulação e de apreensão de um jornal no país. Esse ato, publicado em 27 de março de 1809, instituía também o veto à crítica (além da censura já existente). Posteriormente, em 1811, surgiria o jornal Idade d'Ouro do Brasil, cuja linha editorial baseava-se em uma política de autocensura (Mattos, 2005: 101).

Tendo em vista a presença da censura em todo o período colonial brasileiro, Costa diz que o controle das ideias e das manifestações de crença, sentimento e crítica foi estabelecido em terras brasileiras desde os primeiros tempos, por meio da ação da Igreja e do Estado. A censura se tornou, assim, uma prática cotidiana e ritualizada, que foi incorporada pela concepção de exercício do poder. Nas palavras de Costa, a censura:

"Burocratizou-se, ajudando a perpetuar o desprezo das elites dirigentes para com a opinião pública, o menosprezo pelo desenvolvimento do pensamento crítico e a discriminação da população e de seus valores culturais, suas formas de sociabilidade e seus discursos" (Costa, 2006: 34). 
Por isso, pode-se dizer que o país desenvolveu, no interior de suas instituições, uma profunda necessidade de negociação com os trâmites do poder. Como resultado, a produção cultural tornou-se predominantemente subalterna e dependente, tendo se desenvolvido certa cumplicidade da sociedade em relação aos mecanismos de coerção. As raízes coloniais da censura no Brasil legaram - segundo as palavras de Costa - uma "herança mal digerida de um controle absolutista e inquisitório" (Costa, 2006: 35).

De modo correlato, desde o período colonial, a imprensa brasileira pode escolher entre assumir-se independente, ameaçando sua própria existência, ou ser conivente com o poder e viver à sobra de regimes autoritários (Moraes, 2005: 88 apud Mattos, 2005: 102). Tal ideia, fundamental à compreensão da relação entre o jornalismo e os mecanismos de controle da informação ao longo da História brasileira, será de grande importância ao desenvolvimento das reflexões presentes neste artigo.

\section{O controle da informação: o Estado e as empresas}

A pergunta “a censura acabou?”, colocada por Paolo Marconi (1980: 113) na época de distensão política do regime militar e, portanto, ainda no calor do momento dos acontecimentos da ditadura, discute os limites do final de censura no período que foi encabeçado pelo presidente Geisel na segunda metade da década de 1970. Naquele momento, o autor ainda se encontrava muito próximo da ação da censura política à imprensa e sob a ditadura (vale notar que Marconi escreve o livro do qual extraímos a referida citação entre 1978 e 1979).

Não obstante, a pergunta do autor é atual ainda hoje. Obviamente, o tipo de controle sobre a informação e sobre o trabalho dos jornalistas sofreu modificações - uma vez que, como vimos, durante a ditadura a censura à imprensa era oficial e burocratizada, exercida pelo próprio Estado.

Segundo Mattos, embora a Constituição de 1988 tenha representado o fim da censura policial e a extinção do Serviço de Censura da Polícia Federal, continuam sendo praticadas no Brasil medidas de retaliação política e econômica aos meios de comunicação, mesmo após o fim do regime de ditadura militar. Nesse sentido, o autor descreve novas ameaças à liberdade de imprensa e tentativas, diretas ou indiretas, de controlar os meios de comunicação (Mattos, 2005: 19). 
Porém, novas ameaças à liberdade de expressão têm surgido não somente no Brasil, como também em outros países. Por isso, antes de aprofundarmos as especificidades do caso brasileiro, é necessário tratar de alguns episódios e tendências em escala internacional.

Nesse sentido, um dado interessante apontado por Mattos é que, a partir de 1992, a imprensa mundial passou a ser questionada principalmente quanto ao que diz à privacidade de pessoas públicas, como artistas e autoridades. Exemplo disso é o episódio ocorrido na Inglaterra, há dezenove anos, quando, devido à divulgação de escândalos envolvendo a família real, o governo inglês adotou legislação específica para enquadrar a imprensa em crimes de "intrusão física" e "cobertura dissimulada". Houve imediata reação por parte de proprietários e editores de jornal em contestação à possibilidade de censura (Mattos, 2005: $55)$.

Ainda de acordo com Mattos, nos Estados Unidos, a garantia da privacidade do cidadão está ligada à ética do profissional de imprensa ou da empresa de comunicação em que trabalha. A privacidade não pode ser posta em termos legais no país, uma vez que a Primeira Emenda da Constituição norte-americana garante a liberdade de expressão sem restrições. Conforme Mattos, as questões éticas e a responsabilidade jornalística, aliás, vem sendo alvo de debates nos Estados Unidos por vários anos (Mattos, 2005: 55).

Citando Fernando Herrero-Tejedor (1993), procurador do Tribunal Constitucional da Espanha, Mattos aponta que o conceito jurídico de privacidade é recente e tem origem norte-americana, tendo sido empregado pela primeira vez em 1890, em um artigo publicado Harvard Law Review. Segundo Herrero-Tejedor, Na Espanha, por exemplo, a liberdade de expressão é uma garantia constitucional, mas que possui limites estabelecidos pela própria Constituição do país (artigo 20.4) em relação, entre outros aspectos, ao respeito à privacidade (Herrero-Tejedor, 1993 apud Mattos, 2005: 55).

Voltemos, agora, ao caso do Brasil. Vale observar, dessa forma, que as tensões entre liberdade de expressão e privacidade também se verificam no Brasil. Célebre exemplo disso é o caso em que o cantor e compositor Roberto Carlos conseguiu que a justiça brasileira proibisse a publicação da história de sua vida pelo jornal ultrasensacionalista Notícias Populares (Mattos, 2005: 55).

A respeito das pressões de ordem econômica (e mesmo política) exercidas sobre os veículos de comunicação, um fator fundamental apontado por Mattos é o fato de que, desde o início dos anos 1970, o governo tem sido identificado como o maior anunciante 
individual do país. Já em 1980, por exemplo, o Estado possuía 82 das 200 maiores empresas não-financeiras do Brasil - as quais se caracterizavam também como grandes anunciantes nos veículos de comunicação. São palavras de Mattos:

"Promovendo reformas bancárias e estabelecendo leis e regulamentações específicas, o Estado aumentou sua participação na economia como investidor direto em uma série de empresas públicas e passou a ter à sua disposição, além do controle legal, todas as condições para influenciar os meios de comunicação, mediante pressões econômicas e políticas" (Mattos, 2005: 36).

Nesse sentido é que Mattos destaca que, no Brasil, o financiamento dos meios de comunicação de massa tem sido, na realidade, um mecanismo poderoso de controle estatal. Além disso, o governo possui poder de barganha junto a questões como a concessão de licenças para a importação de materiais e equipamentos e o provisionamento de subsídios para essas importações (Mattos, 2005: 42).

Além das referidas formas de influências e pressão sobre os meios de comunicação, dispositivos legais também se configuram como atentados contra a liberdade de expressão. Trata-se de uma espécie de "censura judicial", que se tem verificado em diversos casos hoje em dia. A respeito de propostas legais que podem cercear o exercício da liberdade de imprensa, Sérgio Mattos cita projetos como, por exemplo, o da Lei Mordaça. Tais questões são suscitadas por debates como aqueles em torno da criação do Conselho Federal de Jornalismo, da Agência Nacional do Cinema e do Audiovisual (Ancinav) e da Lei Geral de Comunicações (Mattos, 2005: 23 a 33).

A título de exemplo, destacaremos aqui, pela relevância do episódio, o caso do projeto da "Lei Mordaça". Em 1997, foi criado o projeto de lei $\mathrm{n}^{\circ}$. 2961-b - apelidado de "Lei Mordaça" - com duas versões, uma da Câmara e outra do Senado. Esse projeto propunha uma modificação da Lei 4.898/65, que tratava de abuso de autoridade. Segundo o projeto, membros do Ministério Público, do Tribunal de Contas e autoridades policiais ou administrativas estariam proibidos de revelar aos meios de comunicação informações de que tenham conhecimento em razão do cargo que ocupam (Mattos, 2005: 23).

Para Mattos, "é preocupante o ressurgimento da censura prévia no Brasil, incluídos aqui as tentativas de aprovação da "Lei Mordaça" e o uso de outras ferramentas econômicas, jurídicas e policiais para intimidar a imprensa e os jornalistas" (Mattos, 2005: 165). Além disso, há também uma nova forma de censura que, sem contar com a repressão policial, envolve todos os tipos de pressões e constrangimentos possíveis, além de condenações e prisões de jornalistas em todo o mundo. 
Exemplo dessas novas práticas é o caso do jornalista Alvanir Ferreira Avelino, que foi condenado, em 2003, a cumprir pena de dez meses e quinze dias de detenção em regime semi-aberto por causa do teor de reportagens e editoriais escritos no jornal Dois Estados, de Miracema. O caso ganhou repercussão internacional, fazendo com que a Sociedade Interamericana de Imprensa (SIP) manifestasse preocupação com essa detenção, bem como com relação às prisões de outros jornalistas que ocorreram, principalmente, na América Latina. Segundo a SIP, essas condenações motivam a autocensura e inibem a imprensa no exercício do papel de vigilante do governo (Mattos, 2005: 165).

A interferência da Justiça como forma de cercear a liberdade de expressão ganhou evidência, em 2009, por ocasião da censura imposta, por decisão judicial do desembargador Dácio Vieira, ao jornal O Estado de S. Paulo, que ficou proibido de publicar notícias sobre as denúncias de corrupção envolvendo o então presidente do Senado, José Sarney. A respeito desse episódio, Eugênio Bucci afirma:

\begin{abstract}
"É uma ironia mais que perversa. Nenhuma das reportagens do Estadão sobre os desmandos no Senado faltou com a verdade. Nenhuma de suas notícias foi mentirosa. E o que é que o jornal ganhou ao final de sua brilhante trajetória? A mordaça. É como se, por ter sido "inimigo" das instituições, levasse o castigo merecido. [...] A culpa, como dizem os homens do poder, é sempre da imprensa" (Bucci, 2009: 76).
\end{abstract}

Outro caso famoso envolvendo a ação judicial foi a condenação, em 2005, do radialista Jorge Reis da Costa, nacionalmente conhecido como Jorge Kajuru. Ele foi sentenciado a dezoito meses de detenção em regime aberto e ao pagamento de 200 diasmulta (equivalente a seis salários-mínimos e meio) por difamação. A acusação foi baseada no fato de que, em seu programa, o radialista teria classificado a Organizações Jaime Câmara, afiliada à Rede Globo, de "oportunista", pela forma como teria obtido os direitos de transmissão do campeonato goiano de futebol (Mattos, 2005: 166).

Observando a ocorrência de situações semelhantes, a Federação Nacional dos Jornalistas (Fenaj) afirmou que, no Brasil, confunde-se liberdade de imprensa com liberdade de "empresa". Nesse sentido, a Fenaj também alertou que, para existir liberdade de imprensa,

“[...] É preciso, também, que o jornalista possa, no exercício diário de sua profissão, ter autonomia e condições dignas de trabalho, que incluem, entre outras, emprego, salário decentes, proteção à saúde e relações trabalhistas respeitosas" (Fenaj, 2005. Apud: Mattos, 2005: 168).

Chegamos, a partir das ideias propostas acima, à questão da influência das empresas de comunicação sobre a configuração da liberdade de imprensa. Para refletirmos 
sobre tal quadro, voltemos ao período de ditadura militar no país. Maurício Maia de Souza, em sua dissertação de mestrado, faz apontamentos muito relevantes que desmistificam o papel "heróico" atribuído aos jornalistas que atuaram durante o período de ditadura (Souza, 1999: 14). Segundo o autor, a ideia de que tenha havido um movimento de resistência, por parte da imprensa em geral, em relação às pressões do governo é falsa, uma vez que apenas uma pequena parte dos veículos foi posta sob cesura prévia (Souza, 1999: 14).

Isso quer dizer que grande parte dos periódicos tinha "bom comportamento", praticando a censura internamente, nas redações. De acordo com Souza (1999), a grande imprensa, de forma geral, apoiou o regime militar, o que de fato fica claro pelo apoio por ela prestado ao golpe de 1964. Além disso, os empresários da grande imprensa, inseridos na lógica de mercado e, portanto, preocupados com seus lucros, não queriam ter problemas com anunciantes, com pressões e cerceamentos exercidos pelo governo, com os prejuízos financeiros causados pelos cortes dos censores às suas edições, etc. (Souza, 1999: 35 e 36). Por esse motivo, calaram-se.

É preciso, pois, ter em mente essa trajetória histórica do jornalismo brasileiro para se pensar sobre a Comunicação atualmente. A visão de Claudia Rodrigues (2002: 130), ao afirmar que o que chama de "morte do jornalismo" começou com o fim da ditadura militar, pode parecer desconsiderar o fato de que, durante aquele período, a imprensa nem sempre resistiu aos mandos e desmandos do Estado.

De qualquer forma, sua afirmação é extremamente válida por destacar a crescente influência das assessorias de imprensa sobre o jornalismo e as pressões, cada vez mais intensas, surgidas pelos conchavos firmados entre empresários da comunicação e publicitários e anunciantes.

Nesse cenário, a autora aponta que o jornalismo passou a ser uma grande encenação, o que se deve a "um mercado excessivamente preocupado em alimentar a voracidade da doutrina econômica". Segundo ela, isso leva a todo tipo de manipulação na produção da notícia. Temos, pois, um controle da informação, ameaçando a liberdade de imprensa e de expressão, que se institui no interior das redações (Rodrigues, 2002: 133).

\section{Mais uma reflexão: as perspectiuas da profissão}

Ao longo deste artigo, dedicamo-nos a abordar os mecanismos de controle que afetam a produção jornalística, os diferentes mecanismos de censura e as ameaças à 
liberdade de expressão. Como também vimos, não é apenas o Estado que atualmente possui ferramentas para controlar os conteúdos veiculados pela mídia. Do mesmo modo, ele não é o único interessado em fazê-lo, haja vista as pressões que operam no interior das empresas jornalísticas, visando à efetivação de seu papel na lógica de mercado em que se inserem e gerando conflitos entre interesses comerciais e editoriais.

Logo, verifica-se, assim, que o campo jornalístico é um espaço marcado por disputas por um poder de influência, de disciplinar, de controlar ${ }^{2}$. Dessa maneira, parecenos claro pensar na importância da formação do profissional de imprensa, que deverá estar preparado para lidar com a conjuntura aqui tratada.

Ademais, discutir os grandes problemas enfrentados pelos jornalistas ao longo da História do Brasil, abordando a evolução dessa atividade, implica também na discussão da regulamentação da profissão no país, assunto posto em destaque desde 2009, quando da decisão do Supremo Tribunal Federal de derrubar a exigência do diploma de jornalista para o exercício da profissão.

Não obstante a existência de argumentos favoráveis à não obrigatoriedade do diploma de jornalista que evocam princípios democráticos para justificar sua posição, alegando que a exigência de formação superior vai contra a liberdade de expressão, é preciso notar que tal pensamento não considera a especificidade do jornalista enquanto mediador do debate público.

Perseu Abramo (1987) também chama a atenção para o fato de o jornalismo ser uma profissão específica - e não uma atividade geral -, que exige formação especializada, justamente por se tratar de um processo complexo. O autor aponta, ainda, que a necessidade de formação para os jornalistas, da qual o diploma de curso universitário é um indicativo, deve aumentar, pois cresce a complexidade do mundo (sendo o mundo o que constitui o conteúdo das informações) e dos métodos de produção e difusão das informações. Para Abramo (1987), esse quadro não tem relação com o direito de ter e emitir opiniões.

De fato, é interessante notar, que todos são livres para ter e expressar suas opiniões (e, para isso, não é necessário qualquer nível de formação) e que esse direito não é característica do jornalismo. Tal princípio associa-se ao grau de democracia de cada sociedade. O jornalismo, por sua vez, é feito inclusive de opiniões, mas não é apenas isso.

\footnotetext{
${ }^{2}$ Neste caso, referenciamo-nos pelas ideias propostas por Mayra Rodrigues Gomes em Poder no Jornalismo
} (2003). 
A exigência do diploma para os jornalistas, aliás, significa assumir que o jornalismo é uma profissão específica, cuja eficiência, equilíbrio e qualidade podem e devem ser cobrados pela sociedade.

De acordo com Abramo (1987), se não há espaço para a expressão de opiniões variadas por meio da imprensa, esse problema deriva do regime de concentração de propriedade dos veículos de comunicação no país. Certamente, essa concentração é prejudicial à democracia e prejudica a qualidade do jornalismo. A obrigatoriedade do diploma, por sua vez, opera justamente em sentido contrário.

Por tudo isso, pode-se apontar aqui que a defesa do diploma de jornalista atende à própria complexidade dessa profissão. Além disso, é coerente à ideia do jornalismo enquanto espaço de mediação. A polêmica em torno do diploma no Brasil, sem dúvida, é marcada pela divisão do debate entre interesses patronais e sindicais. E não há como negar que o fim da exigência de diploma de jornalista é interessante aos empresários. Isso porque, como destacado por Clóvis Augusto Melo, “jornalistas sem diploma são sinônimo de mão-de-obra barata" e, na indústria do entretenimento, não é preciso formação sofisticada para se adequar à baixa qualidade do que é chamado de jornalismo (Melo, 2002: 135).

Mas, além disso, esse debate em torno do diploma também reflete um contexto mais amplo vivido hoje pelo mundo, de "pulverização" e de deslegitimação do discurso jornalístico, como destaca Sylvia Moretzsohn (2003). No entanto, até defensores da não obrigatoriedade do diploma, como Tuffani - que não considera razoável a exigência de curso superior ao exercício da profissão - defende "uma regulamentação do jornalismo voltado ao desenvolvimento humano".

Para Claudia Rodrigues, "o jornalismo passou a ser uma grande encenação" (Rodrigues, 2002: 131). Como defende a autora, isso não se deve à obrigatoriedade ou não do diploma de jornalista, mas à lógica econômica à qual estão subordinadas as empresas de comunicação. E, sem dúvida, o curso de nível superior não é garantia de que o jornalismo será exercido de forma a se voltar ao desenvolvimento humano. Mas é um passo nessa direção.

Negar o diploma significa negar os esforços no sentido desse desenvolvimento. Ademais, certamente são bem-vindos e necessários os esforços em direção à melhoria dos cursos de jornalismo do país. É importante pensar em ambientes acadêmicos que, ao invés 
de favorecer uma cultura homogeneizadora, permitam o livre debate de ideias e o questionamento dos modelos de produção jornalística postos.

Finalmente, é por meio de suas rotinas de produção da notícia, alicerçadas sobre a forte estrutura das empresas jornalísticas, que essas corporações "naturalizam o exercício do seu poder simbólico", de acordo com Sylvia Moretzsohn (2003: 10). Como defende a autora, é necessário que se recupere o papel de mediador do jornalismo, investindo-o de seu sentido político.

Para isso, é necessário enfrentar as bases sobre as quais as grandes corporações da mídia se estruturam. E, claro, retomando a lógica de Perseu Abramo (1987): combater a estrutura de concentração de propriedade de meios de comunicação, esta sim prejudicial à experiência democrática e à livre expressão de opiniões.

\section{Referências Bibliográficas}

ABRAMO, Perseu. Jornalismo: profissão específica ou atividade geral?. Folha de S. Paulo, São Paulo, 2 de outubro de 1987. Disponível em :

<http://www2.fpa.org.br/portal/modules/news/article.php?storyid=56>. Acesso em 13 ago. 2011.

BUCCI, Eugênio. Quando só a imprensa leva a culpa (mesmo sem tê-la). Revista Estudos Avançados, São Paulo, nº 67 / dezembro de 2009, pp. 61-78.

FILHO, Ciro Marcondes. O capital da notícia. São Paulo: Ática, 1986.

GOMES, Mayra Rodrigues. Poder no Jornalismo. São Paulo: Hacker: EDUSP, 2003.

MATTOS, Sérgio. Mídia controlada: a história da censura no Brasil e no mundo. São Paulo: Paulus, 2005.

MARCONI, Paolo. A censura política à imprensa brasileira (1968-1978). São Paulo, Global, 1980. 
MELO, Clóvis Augusto. Patrão, o maior interessado. In: Formação Superior em

Jornalismo: uma exigência que interessa à sociedade. Federação Nacional dos Jornalistas (Org.) Florianópolis: Imprensa da UFSC, 2002.

MORETZSOHN, Sylvia. Jornalismo, mediação, poder: considerações sobre o óbvio surpreendente. In: Anais do I SBPJor - A institucionalização da pesquisa em jornalismo no Brasil. Brasília: UnB, 2003.

RODRIGUES, Claudia. O patronato e as novas coalizões. In: Formação Superior em Jornalismo: uma exigência que interessa à sociedade. Federação Nacional dos Jornalistas (Org.) Florianópolis: Imprensa da UFSC, 2002.

SODRÉ, Nelson Werneck. A História da Imprensa no Brasil. $3^{\text {a }}$ edição, Rio de Janeiro, Martins Fontes, 1983.

SOUZA, Maurício Maia de. Henfil e a censura: o papel dos jornalistas. São Paulo: ECA/USP, 1999 (dissertação de mestrado). 